\title{
Investigating Spinner Dolphin (Stenella longirostris) Occurrence and Acoustic Activity in the Maui Nui Region
}

\section{OPEN ACCESS}

Edited by:

Adrienne Copeland,

NOAA's Office of Ocean Exploration and Research, United States

Reviewed by:

Antoine De Ramon N'Yeurt, University of the South Pacific, Fiji Ester Quintana-Rizzo,

Simmons University, United States

${ }^{*}$ Correspondence:

Megan M. McElligott meganmce@hawaii.edu

Specialty section: This article was submitted to Ocean Observation,

a section of the journal

Frontiers in Marine Science

Received: 30 April 2021

Accepted: 20 August 2021 Published: 10 September 2021

Citation:

McElligott MM and Lammers MO (2021) Investigating Spinner Dolphin (Stenella longirostris) Occurrence and Acoustic Activity in the Maui Nui Region. Front. Mar. Sci. 8:703818. doi: 10.3389/fmars.2021.703818

\author{
Megan M. McElligott ${ }^{1,2 *}$ and Marc O. Lammers ${ }^{2,3}$ \\ 'Hawai'i Institute of Marine Biology, University of Hawai'i at Mānoa, Kāne'ohe, HI, United States, ${ }^{2}$ Oceanwide Science \\ Institute, Honolulu, HI, United States, ${ }^{3}$ Hawaiian Islands Humpback Whale National Marine Sanctuary, Kinei, HI, \\ United States
}

Hawaiian spinner dolphins (Stenella longirostris) rest during the day in the islands' coastal waters where they are susceptible to human disturbance. Due to concerns over the negative impacts of human activity, the Pacific Islands Regional Office of the National Oceanic and Atmospheric Administration (NOAA) has proposed a 50yard approach rule for spinner dolphins and is also considering time-area closures of certain important spinner dolphin resting areas. However, gaps still persist in the understanding of how spinner dolphin populations on different Hawailan Islands use coastal waters, raising questions about the efficacy of the proposed rules. To better understand how spinner dolphins use the waters in the Maui Nui region (Maui, Moloka'i, Lāna'i, and the 'Au'au channel), a study was conducted using a combination of passive acoustic monitoring and vessel surveys to document spinner dolphin occurrence and movements. Bottom-moored acoustic recorders were deployed at eight locations in Maui Nui, and at one previously established resting bay off west O'ahu for comparison. The amount of whistles, clicks, and burst pulses at each location was quantified and averaged by the hour of the day. Acoustic activity was greater at the O'ahu site than at any of the Maui Nui sites, and was greatest between sunrise and noon. Acoustic activity and vessel surveys both reveal that spinner dolphins occur and exhibit resting behaviors in the 'Au'au channel between Maui and Lāna'i, and also along west Maui and southeast Lāna'i. Spinner dolphins resting in a channel between islands appears to be unique to Maui Nui and differs from resting patterns described along Hawai'i Island and O'ahu. Because spinner dolphins appear to use both the coastlines and the channel to rest in Maui Nui, the 50-yard approach rule appears to be a more suitable management option for the region than time-area closures.

Keywords: passive acoustic monitoring, spinner dolphin, Maui Nui, Stenella longirostris, acoustic activity

\section{INTRODUCTION}

The spinner dolphin (Stenella longirostris) is a well-studied odontocete species distributed across tropical and subtropical oceans of the world. Hawaiian spinner dolphins are considered genetically distinct from other populations in the Pacific Ocean and are found throughout the island chain (Andrews et al., 2010). Past research off the Kona coast of Hawai' $\mathrm{i}$ Island has established that spinner 
dolphins are reliably found along the island's sloping coastlines where they follow predictable, daily behavioral routines (Norris et al., 1994). These routines consist of nocturnal foraging, during which spinner dolphins feed on vertically migrating mesopelagic fish, and mesopelagic and epipelagic squid typically found in deeper waters of the island slopes along the 1000-fathom contour (Klinowska, 1991; Norris et al., 1994; Benoit-Bird et al., 2001; Benoit-Bird and $\mathrm{Au}, 2003)$. By dawn, the dolphins transition to a bout of increased aerial activity and zig-zag swimming, or frequent changes in their direction of travel (Norris et al., 1994). The highly dispersed school then tightens into subgroups as it moves into shallower, protected bays to rest (Norris et al., 1994).

Aerial surveys off the Kona coast in 1979-1980 suggested that bay selection was opportunistic and showed a positive correlation between the closeness of deep water to shore and the presence of dolphins in nearby coves (Norris et al., 1994). However, these surveys also showed that if visibility or weather conditions were poor, the dolphins would relocate to calmer bays. While in the bays, spinner dolphins confine their movements to areas over white coral sand and avoid dark reefs. This preference for shallow bays with low rugosity has also been demonstrated in modeling of spinner dolphin habitat in the Main Hawaiian Islands (Thorne et al., 2012). The need for clear visibility is attributed to the dolphins' shift from primarily employing echolocation to monitor their environment, to relying more on vision in the resting state (Norris et al., 1994).

Since the aerial surveys, it has been shown that spinner dolphins off some of the other Hawaiian islands also exhibit predictable patterns of behavior (Benoit-Bird and $\mathrm{Au}, 2003$; Bazúa-Durán and Au, 2004; Lammers, 2004, 2019; Tyne et al., 2014). However, there is another, more cryptic group that occupies the waters of the broader Maui Nui region between the islands of Maui, Moloka 'i, and Lāna' $i$, whose behavioral use of the coastline and inter-island channels is variable and poorly understood. This area is of particular interest because Maui Nui has a uniquely shallow bathymetry compared to the steeper slopes and deep waters of the other Hawaiian Islands where spinner dolphins occur (Price and Elliott-Fisk, 2004). Therefore, it is unclear how these dolphins complete their day/nighttime behavioral cycle, given the comparatively farther distance to deep, island-slope waters. The effect of varying habitat availability on spinner dolphin behavior can be seen at Midway Atoll. There, dolphins compensate for limited resting bays and vast areas of open ocean by maintaining both geographic and group fidelity and minimizing movement between atolls (Karczmarski et al., 2005). Additionally, a recent publication of spinner dolphin sightings and photo-identification data collected between 1996 and 2019 identified south Lāna'i and west Maui as two hotspots of dolphin presence in Maui Nui (Stack et al., 2020). Spinner dolphins were observed milling and traveling along west Maui; and milling, traveling, or resting along Lāna'i and in the 'Au'au channel. This suggests that a variant behavioral routine in the Maui Nui spinner dolphin population might be present.

The west Maui coast has been subject to intense urbanization and human activity over the past three decades with the construction of numerous resorts and the growth of recreational water activities. These activities, which include whale-watching tours, snorkeling tours, parasailers, and recreational boaters, mostly occur in the shallow waters typically preferred by spinner dolphins for daytime resting. This is a concern because human activity can interrupt dolphin resting periods or displace them from their prime resting locations, and because spinner dolphin resting behavior consistently takes place near human activity, they may be impacted by human disturbance (Tyne et al., 2014, 2017).

Studies conducted off the Kona coast of the island of Hawai' $i$ have shown that human activities frequently interrupt dolphins at rest, and bays with dolphin-centric human activities have greater amounts of dolphin acoustic activity during times typically characterized by relative silence, suggesting a reduction in rest (Courbis and Timmel, 2009; Heenehan et al., 2016a,b). Dolphins off Mākua Beach, O'ahu have also shown a decrease or delay of rest possibly in response to swimmers (Danil et al., 2005). In response to these concerns, the National Marine Fisheries Service has proposed a 50-yard approach limit for Hawaiian spinner dolphins and possible targeted time-area closures of important resting habitats (NOAA, 2016). However, in order to establish the most effective regulations for Hawai'i's spinner dolphins, current dolphin habitat-use patterns must be better understood for each island.

Like those of many delphinids, spinner dolphin acoustic signals can be classified into three broad categories: whistles, echolocation clicks, and "burst pulse" click trains (Lammers and $\mathrm{Au}, 2003$; Lammers and Oswald, 2015). Frequency modulated, tonal whistles and "burst pulse" click trains are the main types of acoustic signals in social interactions, and echolocation clicks are primarily used as biosonar while foraging or navigating the environment (Lammers and Au, 2003; Lammers et al., 2006). When resting, spinner dolphins remain fairly silent but increase their acoustic activity while traveling or foraging (Norris et al., 1994; Bazúa-Durán and Au, 2004). The variation in timing and type of acoustic behavior can be used to determine the spinner dolphins presence in an area and infer their social state (Heenehan et al., 2016a, 2017). As a result, spinner dolphins are well suited for monitoring using autonomous recorders to establish their patterns of occurrence in an area of interest (Lammers and Munger, 2016).

The objective of this study was to determine whether spinner dolphins in the Maui Nui region exhibit similar daily behavioral patterns as those previously described along the Wai'anae coast of O'ahu (Lammers, 2004) and the Kona coast of Hawai'i Island (Norris et al., 1994; Tyne et al., 2015). In other words: do spinner dolphins in the Maui Nui region occupy nearshore habitats for socializing and resting as they do elsewhere in Hawai' $i$, and which areas are frequented the most by spinner dolphins. A combination of passive acoustic methods and vessel surveys were employed to characterize spinner dolphin occurrence in the west Maui/south Lāna'i portion of Maui Nui. Passive acoustic monitoring and visual survey methods have been shown to produce equivalent results in presence/absence studies of spinner dolphins off the Kona coast (Heenehan et al., 2016b). Passive acoustic monitoring has the added benefit of providing long-term, continuous data collection, resulting in good temporal resolution of trends in 
animal presence (Lammers and Munger, 2016), but it is spatially limited to the monitored location. The vessel surveys in this study were therefore used to supplement the acoustic data in order to obtain a broader spatial perspective of spinner dolphins' use of Maui Nui.

\section{METHODOLOGY}

\section{Passive Acoustic Monitoring}

Ecological Acoustic Recorders (EARs) (Lammers et al., 2008b) were used to monitor the acoustic presence of spinner dolphins at eight locations in Maui Nui and one location off the Wai'anae coast of O'ahu (Figure 1). EAR deployment locations were selected by soliciting input from commercial and private ocean users familiar with Maui Nui's spinner dolphins and from the authors' personal experience. These locations were selected to understand the relative importance of each area to the dolphins' daily routine. The O'ahu location was selected to represent the acoustic activity pattern that can be expected at an established spinner dolphin resting bay. The measured detection range of each EAR location varied with local propagation conditions and ambient noise levels, and fell between approximately 500 and $2000 \mathrm{~m}$, based on in situ measurements obtained by projecting a $4-7 \mathrm{kHz}$ FM tonal signal with a source level of $145.5 \mathrm{~dB}$ re $1 \mu \mathrm{Pa}$ from a vessel at multiple distances (McElligott, 2018). Therefore, it can be assumed that monitored sites did not have overlapping listening ranges. Furthermore, apart from the EAR placed in the middle of the 'Au'au channel, each EAR location detected delphinids occurring within 1-2 km of the coastline, which are predominantly spinner dolphins (Howe and Lammers, 2021). Each EAR was programmed to record at a $10 \%$ duty cycle of $30 \mathrm{~s}$ "on" every $300 \mathrm{~s}$. Because some of the EARs were used as part of parallel studies, sampling rates varied between some instruments, but the minimum frequency range used $(25 \mathrm{kHz})$ was sufficient to capture the fundamental frequencies of spinner dolphin whistles and the lower end of the frequency range of their click trains (Lammers and Au, 2003). All EARs recorded for 2 months or longer (Table $\mathbf{1}$ ).

\section{Analysis of Acoustic Recordings}

Each 30-s EAR recording was visually scanned in the MATLAB program Triton using an FFT length of 1400 points, with 50\% overlap, and a plot length of 15 s (Wiggins, 2003). For each

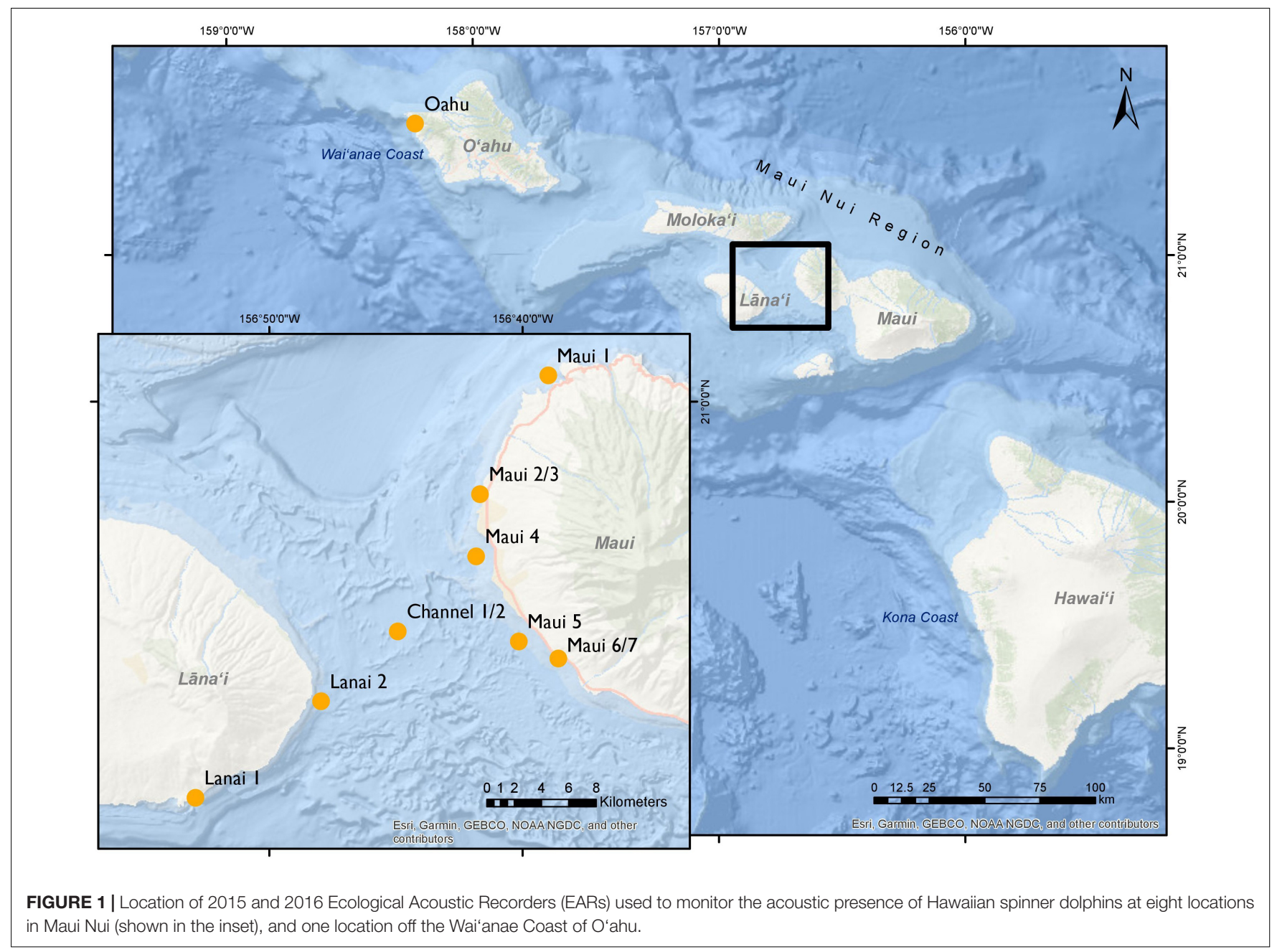


TABLE 1 | Ecological Acoustic Recorders (EARs) were deployed in one location off O'ahu, and eight locations in Maui Nui.

\begin{tabular}{|c|c|c|c|c|c|c|c|}
\hline EAR & Season & Start & End & Sample rate $(\mathrm{Hz})$ & Depth (m) & Latitude & Longitude \\
\hline Oahu & Fall & 10/1/2016 & $11 / 30 / 2016$ & 50000 & 18.0 & 21.53210 & -158.23450 \\
\hline Lanai 1 & Fall & 9/30/2016 & 11/30/2016 & 64000 & 20.9 & 20.73928 & -156.88200 \\
\hline Lanai 2 & Fall & 9/30/2016 & 11/30/2016 & 64000 & 42.2 & 20.80275 & -156.79930 \\
\hline Channel 1 & Winter & 1/18/2015 & 3/18/2015 & 125000 & 70.1 & 20.84877 & -156.74882 \\
\hline Channel 2 & Summer & 6/30/2016 & 8/30/2016 & 64000 & 70.1 & 20.84877 & -156.74882 \\
\hline Maui 1 & Fall & 10/5/2016 & 11/30/2016 & 64000 & 25.5 & 21.01693 & -156.64980 \\
\hline Maui 2 & Winter & 1/15/2016 & 3/16/2016 & 50000 & 11.2 & 20.93892 & -156.69470 \\
\hline Maui 3 & Summer & 6/30/2016 & 8/30/2016 & 64000 & 11.2 & 20.93892 & -156.69470 \\
\hline Maui 4 & Summer & 6/30/2016 & 8/30/2016 & 64000 & 30.0 & 20.89812 & -156.69720 \\
\hline Maui 5 & Summer & 6/30/2016 & 8/20/2016 & 64000 & 43.9 & 20.84208 & -156.66920 \\
\hline Maui 6 & Winter & $1 / 15 / 2016$ & 3/16/2016 & 50000 & 12.0 & 20.83077 & -156.64320 \\
\hline Maui 7 & Summer & 6/30/2016 & 8/30/2016 & 64000 & 12.0 & 20.83077 & -156.64320 \\
\hline
\end{tabular}

Approximately 2 months of recordings were analyzed for each deployment.

The Channel 1 and Channel 2 deployments took place in the same location, as did the Maui 2 and Maui 3 deployments, and the Maui 6 and Maui 7 deployments.

Additional details of the study area are shown in Figure 1.

recording containing dolphin signals, dolphin acoustic activity was quantified using an Acoustic Activity Index (AAI) based on the quantity of whistles, clicks, and burst pulses present and modified from the scalar metric used by Lammers et al. (2013). AAI ranged from 0 to 3.5 with higher index values assigned to recordings that contained more dolphin whistles, clicks, and/or burst pulses (Table 2). For example, an AAI value of 0 indicates that there was no dolphin acoustic activity present in a 30-s recording. The next possible index value of 0.5 was assigned to recordings that contained either no more than 5 whistles, no more than 5 burst pulses, or echolocation clicks present in less than half of the recording. The maximum index value of 3.5 was assigned to 30 -s recordings with at least 10 whistles, and echolocation clicks and burst pulses present. Thus, one index value from Table 2 was assigned to each 30$s$ recording based on the number and type of signals observed in that recording, placing it along a continuum between little or no acoustic activity and a lot of acoustic signaling. The resulting data were compiled to establish the mean acoustic activity index for each hour of every day of each deployment. Using this index allowed the comparison of relative states of acoustic activity at different times of day at different locations within the study area.

Time of day was binned into three "day categories" for analysis in order to reduce temporal autocorrelation within the data. The hours between local sunrise (between 0554 and $0713 \mathrm{~h}$ ) and noon $(1200 \mathrm{~h})$ were defined as "Sunrise-Noon" in order to characterize the acoustic activity of spinner dolphins during the hours in which they are typically traveling from foraging grounds to the nearshore resting bays and beginning their resting behaviors. The hours between noon and local sunset (between 1749 and 1919 h) were defined as "Noon-Sunset" to characterize the acoustic activity of spinner dolphins during the hours in which they transition from resting to traveling offshore to their foraging grounds. The final category, "Night" was defined as the hours between sunset and sunrise, when spinner dolphins engage in foraging behavior (Norris et al., 1994; Tyne et al., 2015).
To determine the ways in which acoustic activity varied among different sites and time of day, these relationships were explored using a generalized additive model (GAM). A beta distribution was selected to describe the response variable due to the non-parametric, positive, and bounded distribution of AAI (Schmid et al., 2013). AAI was divided by 3.5 to fit within the $0-1$ range of a beta distribution. By nature, these data are temporally and spatially autocorrelated, so a componentwise gradient boosted beta regression generalized additive model (boosted GAM) was fit to the data using the gamboostLSS package (Hofner et al., 2014, 2016). Boosted GAMs with beta regressions estimate two model parameters: $\mathrm{mu}$, which estimates the mean

TABLE 2 | Acoustic Activity Index (AAI) based on the quantity and type of Hawaiian spinner dolphin signals within each 30 -s recording.

\begin{tabular}{lc} 
Hawaiian spinner dolphin signals & $\begin{array}{c}\text { Acoustic Activity Index } \\
\text { (range: } \mathbf{0 - 3 . 5 )}\end{array}$ \\
\hline No acoustic activity & 0 \\
$1-5$ whistles & 0.5 \\
Burst pulses only (<5 pulses) & 0.5 \\
Clicks only in less than half the recording & 0.5 \\
$6-10$ whistles & 1.0 \\
Clicks only in more than half the recording & 1.0 \\
Burst pulses only (>5 pulses) & 1.0 \\
Clicks and burst pulses (<5 pulses) & 1.0 \\
$1-5$ whistles and clicks or burst pulses & 1.5 \\
$>10$ whistles & 2.0 \\
Clicks and burst pulses (>5 pulses) & 2.0 \\
$1-5$ whistles and clicks and burst pulses & 2.5 \\
$6-10$ whistles and clicks or burst pulses & 2.5 \\
$6-10$ whistles and clicks and burst pulses & 3.0 \\
$>10$ whistles and clicks or burst pulses & 3.0 \\
$>10$ whistles and clicks and burst pulses & 3.5
\end{tabular}

The index ranges from 0 to 3.5 .

Values increase with increasing acoustic activity, and higher index values indicate spinner dolphins in an awake state. 
acoustic activity index, and phi, which is a precision parameter that adjusts the conditional variance for each predictor (Schmid et al., 2013). Boosted GAMs have built-in variable selection and can be combined with cross-validation techniques to determine the optimal number of boosting iterations and prevent overfitting (Hofner et al., 2016). In addition to site and day category, a spatial spline and cyclic temporal spline were included in the model as initial base-learners to explain variance in AAI due to the longitude and latitude of the EAR, and the month of the year. This type of model has successfully been applied to ecological data to mitigate the complexities of autocorrelated, non-linear data (Maloney et al., 2012; Tyne et al., 2015; Sewe et al., 2017). Statistical tests were performed in the software package $R$ with base (R Core Team, 2015).

\section{Vessel Surveys}

Concurrent with the EAR deployments, vessel surveys and focal follows were used to provide additional detail about the spinner dolphins' movements and behavioral state at different locations in Maui Nui. An initial series of seven surveys was conducted over a 2-week period in August 2016 that covered the west Maui coast and offshore waters where spinner dolphins have been reported. Three additional vessel surveys took place in June of 2017. The survey tracks closely followed the locations of the EAR deployments in order to examine spinner dolphin presence. Each survey began out of Lāhainā Harbor in a 21-ft vessel with two observers on board cruising at 10 knots. When animals were encountered and, if conditions permitted, spinner dolphin groups were followed at a distance of 300-400 m for as long as feasible (at least $15 \mathrm{~min}$ ) with the goal of observing the group through their resting period. As the dolphins were tracked, group size, location, and behavioral state (milling, resting, travel-resting, or traveling) were recorded every $15 \mathrm{~min}$. Milling was characterized by dolphins spending more time at the surface and swimming in varying directions. Resting was defined by the presence of tightly spaced spinner dolphin groups performing coordinated dives that lasted longer than $3 \mathrm{~min}$. Travel-resting was defined by resting groups moving in one general direction, while traveling was defined by the group swimming in a generally straight direction without any resting behavior. Sightings ended when the dolphins were not sighted for more than $15 \mathrm{~min}$. For multistate groups, the dominant behavioral state was applied to the group.

\section{RESULTS}

\section{Passive Acoustic Monitoring}

A total of 191,808 recordings were manually scanned for dolphin acoustic signals, and assigned a value for the AAI. The mean hourly AAI $( \pm S E M)$ is shown for each deployment in Figure 2. The Oahu deployment off Mākua Beach is representative of a previously established spinner dolphin resting bay. Oahu had more than double the mean hourly AAI than the other deployment sites (Figure 2). Of the Maui Nui deployments, Lanai 1, Channel 2, Maui 1, and Maui 4 had the greatest mean hourly

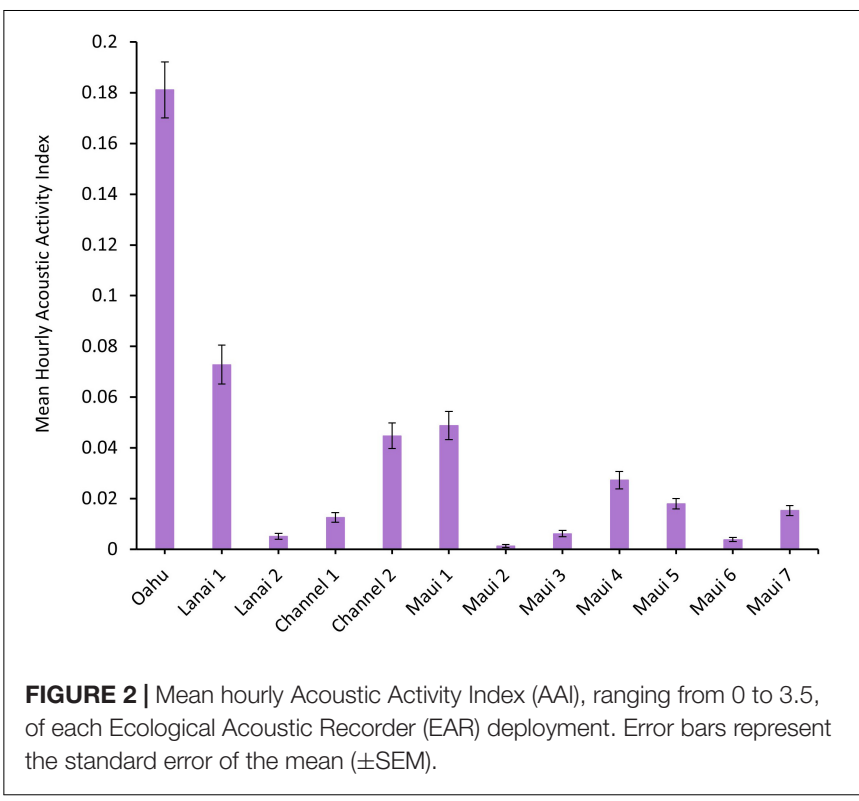

AAI. However, all of the deployment locations contained some level of spinner dolphin acoustic activity.

The greater AAI for the Oahu deployment was also apparent when plotted by hour of the day (Figure 3). Mean AAI peaked at $800-900 \mathrm{~h}$ with a smaller, secondary peak at $1500-1600 \mathrm{~h}$. This bimodal pattern also occurred at the Lanai 1 site with a maximum mean AAI at $1200 \mathrm{~h}$ and a secondary peak at $1500-1600 \mathrm{~h}$, as well as the Channel 2 site with peaks at $900 \mathrm{~h}$ and 1500-1600 h. Maui 1 and Maui 4 had single peaks in acoustic activity at 800-900 h and $1300 \mathrm{~h}$, respectively.

\section{Winter vs. Summer Acoustic Activity}

The seasonality of spinner dolphin acoustic activity was explored at three EAR locations where both a winter deployment and a summer deployment were made. Channel 1 and Channel 2 were winter and summer deployments, respectively, in the same location, as were Maui 2 and 3, and Maui 6 and 7. Each location had an increase in the mean AAI during the summer deployment (Figure 4).

\section{Boosted Beta Regression - Generalized Additive Model}

The base learners selected by the boosted beta regression included: site, day category, the cyclic smoother for month, and the spatial spline (Table 3). Cross-validation determined the optimal number of boosting iterations to be 3153 iterations for $\mathrm{mu}$ (transformed mean hourly AAI) and 719 iterations for phi (variance of transformed mean hourly AAI) in order to prevent over-fitting. Step size was 0.1 for both mu and phi. Partial effects were plotted to illustrate how site, day category, and month each affected mean hourly AAI in the model (Figure 5). Recordings collected from Oahu were predicted to increase mean hourly AAI compared to all other sites. Maui 1 and Lanai 1 were predicted to have slightly negative effects on the AAI, but to a lesser degree than any of the other sites (Figure 5A). The model also predicts 


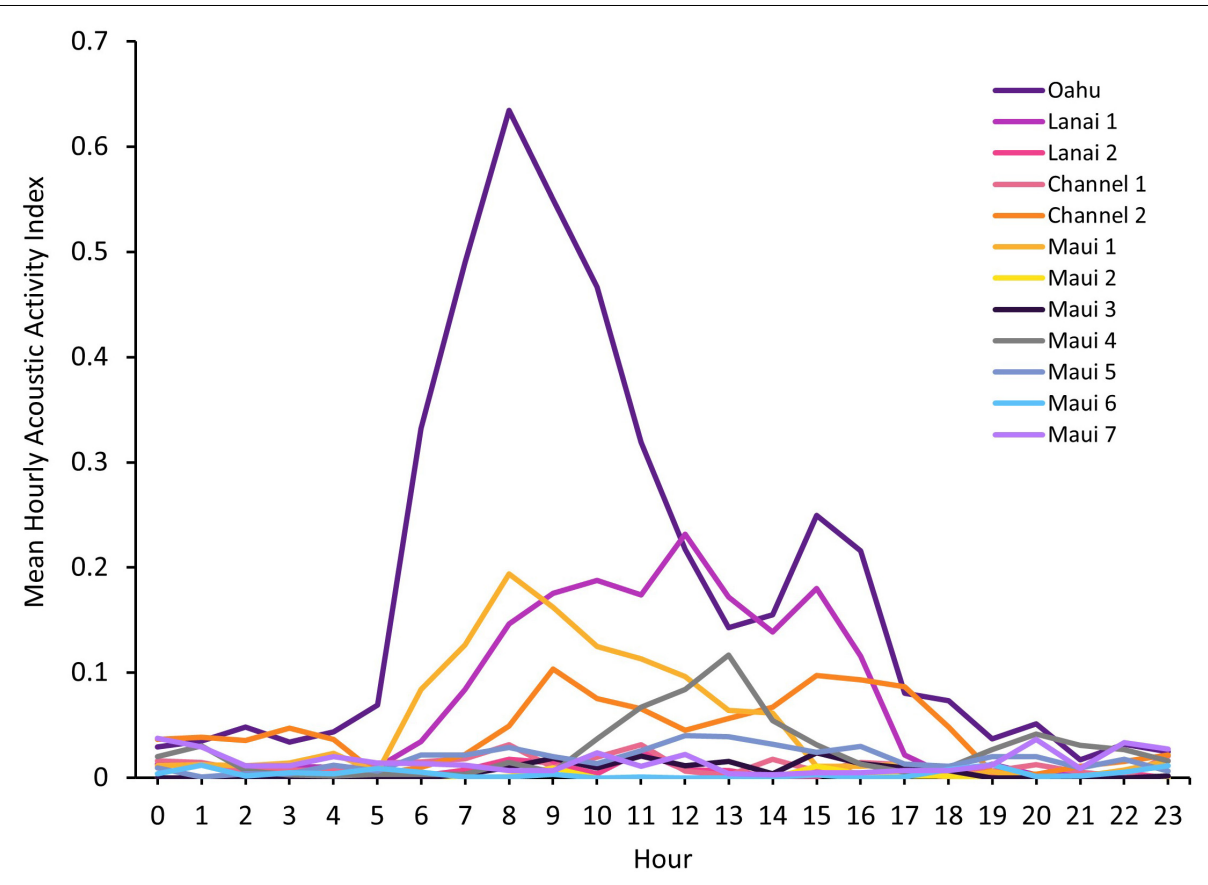

FIGURE 3 | Mean hourly Acoustic Activity Index (AAl), ranging from 0 to 3.5, by hour of day for each Ecological Acoustic Recorder (EAR) deployment. Along the $x$-axis hour 0 begins at midnight, and hour 23 begins at $2300 h$.

that hours that fall between sunrise and noon will have greater mean AAI than those that do not with nighttime hours having the lowest mean AAI (Figure 5B). The cyclic smoother for month reflects the pattern seen in Figure 4 of greater mean hourly AAI in summer months than winter months (Figure 5C).

\section{Maui 1 vs. Lanai 1}

Maui 1 and Lanai 1 were two Maui Nui locations that stood out from the other deployments as having higher mean AAI.

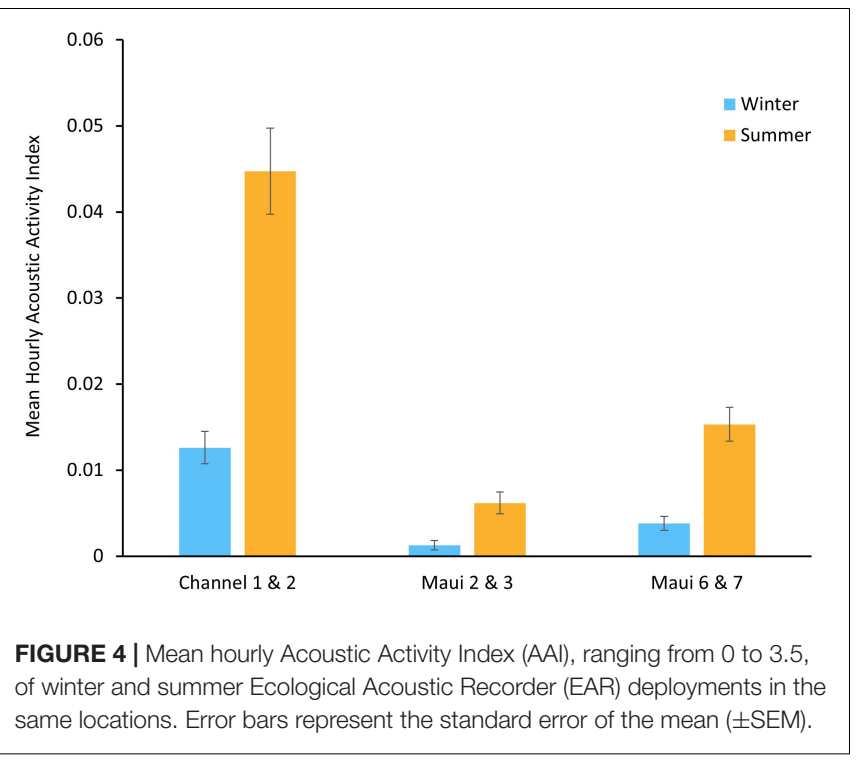

Because these deployments were concurrent, it was possible to compare on an hourly basis, whether spinner dolphin signals were detected only in the bay of Maui 1, only in the bay of Lanai 1 , in both bays, or neither bay. At approximately $40 \mathrm{~km}$ distance from each other, it is unlikely that spinner dolphins recorded in one bay would be recorded in the other bay within the same hour. Therefore, if dolphin signals are consistently observed in both bays simultaneously, then this would imply the presence of two concurrent Lāna'i and west Maui spinner dolphin groups. If dolphin signals are not seen in both bays simultaneously, it would be more likely that one group of spinner dolphins varies spending its time in different parts of Maui Nui.

TABLE 3 | Variables selected in the boosted generalized additive model (boosted GAM).

\begin{tabular}{lccc}
\hline $\begin{array}{l}\text { Model } \\
\text { parameter }\end{array}$ & $\begin{array}{c}\text { Optimal boosting } \\
\text { iterations }\end{array}$ & $\begin{array}{c}\text { Model-selected } \\
\text { variables }\end{array}$ & $\begin{array}{c}\text { Selection } \\
\text { frequency }\end{array}$ \\
\hline $\mathrm{Mu}$ & 3153 & $\begin{array}{c}\text { Latitude, Longitude } \\
\text { Month }\end{array}$ & 0.52 \\
& & Site & 0.22 \\
& & Day Category & 0.21 \\
$\mathrm{Phi}$ & 719 & Site & 0.05 \\
& & Month & 0.51 \\
& & Day Category & 0.29 \\
& & & 0.21 \\
\hline
\end{tabular}

The model parameter, mu, estimates the mean acoustic activity index (AAl) of Hawaiian spinner dolphins, while phi is a precision parameter that adjusts the model's conditional variance for each predictor.

Optimal boosting iterations (mstop) is the number of iterations at which boosting is stopped to avoid overfitting the model. 

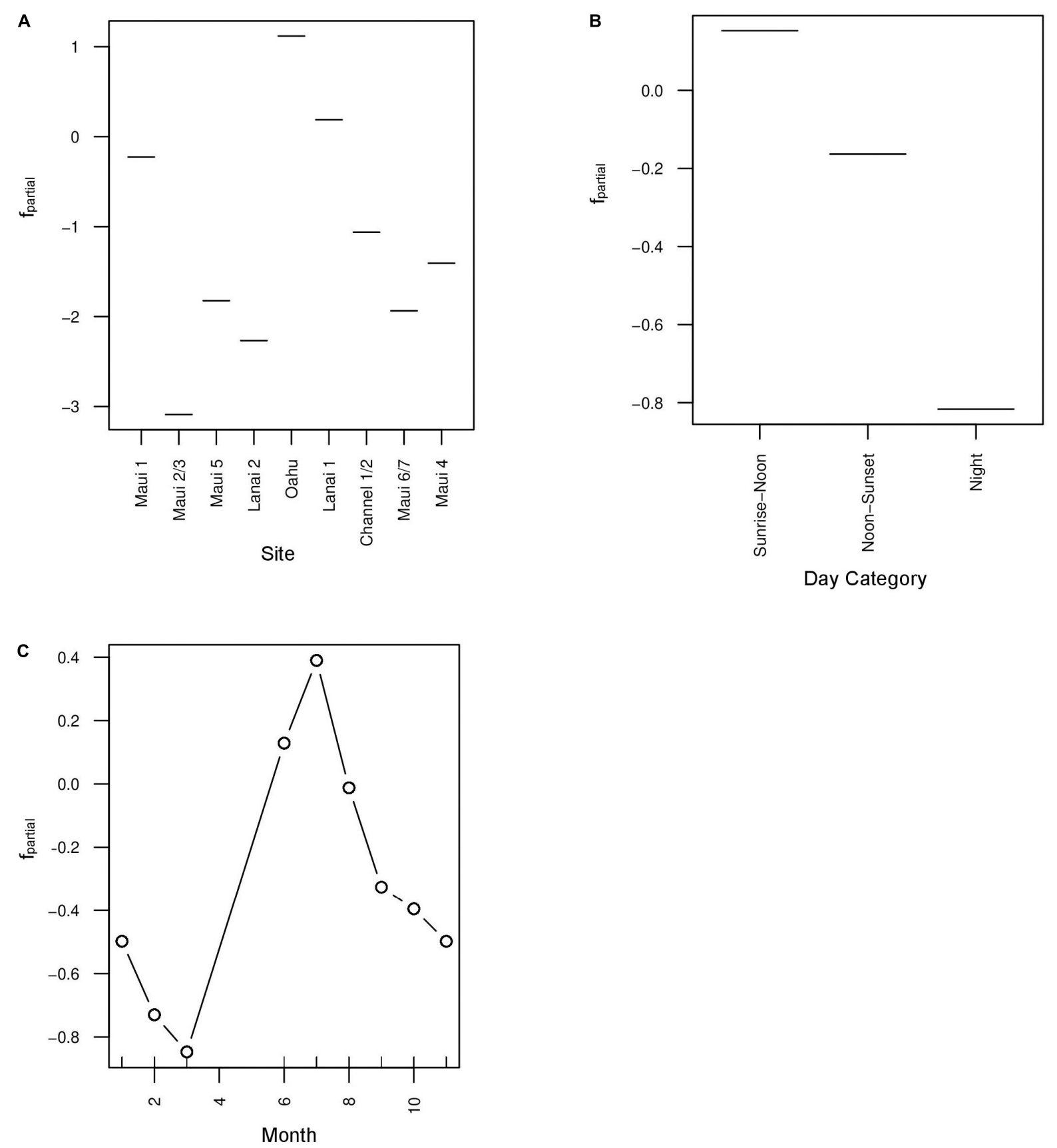

FIGURE $\mathbf{5}$ | Partial effects plots of the mu parameter in the boosted GAM for three selected base learners: site (A), day category (B), and month (C). To apply a beta regression to the model, Acoustic Activity Index (AAl) was divided by 3.5 in order to bound its values between 0 and 1. Month was included as a cyclic smoother to account for variation in acoustic activity within the year.

The percentage of hours in the deployments that included dolphin signals in Maui 1 only, Lanai 1 only, both bays simultaneously, or neither bay were calculated. Of those deployments $73.54 \%$ of hours did not contain dolphin signals at either location, $2.70 \%$ of hours contained dolphin signals at both locations, $12.13 \%$ of hours contained dolphin signals at only Maui 1 , and $11.62 \%$ of hours in the deployment contained dolphin signals at only Lanai 1 . When plotted by the hour of the day during which these detections occurred, dolphin signals were detected in both bays simultaneously between 0000 and $1400 \mathrm{~h}$ (Figure 6). Dolphin acoustic signals were detected during all hours of the day at Maui 1 except for 1800 and $2000 \mathrm{~h}$. The hours with the most Maui 1 only detections occurred between 0600 and $0900 \mathrm{~h}$. Hours with dolphin acoustic signals only at Lanai 1 occurred all day with a peak between 0700 and $1700 \mathrm{~h}$ (Figure 6). 


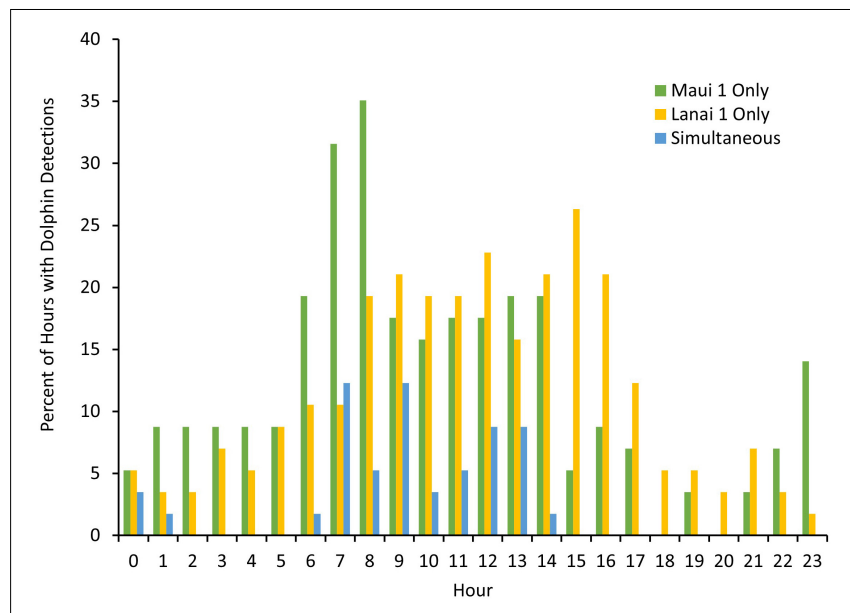

FIGURE 6 | Percent of hours in which Hawaiian spinner dolphin acoustic detections occurred in Maui 1 only, Lanai 1 only, or both bays simultaneously by hour of day from 05 October 2016 to 30 November 2016, a 57-day deployment (where 0 represents midnight, and 23 represents $2300 \mathrm{~h}$ ).

\section{Vessel Surveys}

Out of ten surveys, six had successful spinner dolphin sightings (four from 2016 and two from 2017), of which five involved extended focal follows that allowed the tracking of animals (Figure 7). Generally, the spinner dolphin sightings first occurred in the late morning before noon and continued into the afternoon. Dolphins were typically first seen along west Maui in the late-morning hours between 1100 and $1200 \mathrm{~h}$ and then followed into the 'Au'au channel by early afternoon (Table 4). On two occasions the spinner dolphins were tracked as they moved toward the southeast side of Lāna' $i$ in the late afternoon, at which point the dolphins were steadily traveling toward Lāna'i's south shore (Figure 7). Table 5 shows the dominant behavioral states observed during each vessel survey. All four behavioral states (milling, resting, travel-resting, and traveling) were observed at different times within the focal follows. Spinner dolphins were observed exhibiting resting behavior characterized by long (>3 min), coordinated dives and also milling behaviors in the 'Au'au channel, often changing their direction of travel (Table 5). Resting or travel-resting behavioral states were observed during each sighting except for the shortest sighting on 5 Aug 2016. Traveling was the most frequently observed behavioral state, followed by travel-resting.

\section{DISCUSSION}

Spinner dolphin habitat-use patterns in Maui Nui do not follow the same patterns of consistent use of specific bays that has been documented off the Kona coast of Hawai' $i$ Island and the Wai'anae coast of O'ahu (Norris et al., 1994; Lammers, 2004; Thorne et al., 2012). Based on the combination of passive acoustic monitoring and vessel surveys, the evidence from this study suggests that Maui Nui spinner dolphins utilize a combination of the west Maui coastline, the southeast Lāna'i coastline, and the 'Au'au channel during their daytime resting. The Maui Nui monitoring sites were clearly distinct from the O'ahu site, with lower overall acoustic activity, and a less defined bimodal pattern of daytime acoustic activity. In other words, spinner dolphins did not occupy any of these sites with the same consistency that spinner dolphins do on O'ahu.

The daily use of particular resting bays expressed in the behavioral cycles of spinner dolphins as described for the Kona and Wai'anae coasts is likely to vary somewhat between islands; particularly in areas where the coastal geography and bathymetry do not offer protected bays near foraging grounds. In Maui Nui spinner dolphins appear to move between west Maui and southeast Lāna'i and also occupy the 'Au'au channel between the islands in order to socialize and rest. These patterns were also reflected in the spatial and behavioral analyses of focal follows and photo-identification data presented by Stack et al. (2020). The middle of the 'Au'au channel does not fit the paradigm of a shallow, sheltered resting bay with white sandy bottom as originally described by Norris et al. (1994). However, it is possible that spinner dolphins are able to utilize the Maui Nui region as one large resting area due to the uniquely shallow bathymetry between Maui, Moloka'i, and Lāna'i (Price and Elliott-Fisk, 2004). By using the channel between islands as a resting habitat, spinner dolphins may also be able to increase their distance from human activities that occur along various parts of each coastline. The location of each deployment, as well as the time of day in which an hour occurred, whether it be from sunrise to noon, noon to sunset, or night, a cyclic smoother for month of the year, and a spatial spline were significant predictors of the mean acoustic activity index (AAI). In other words, there were spatial, monthly, and diel patterns in the acoustic activity of dolphins in Maui Nui and also at Mākua Beach on O'ahu. The bimodal nature of dolphin acoustic activity reflects the times during the day that spinner dolphins enter or exit their resting behavior (Lammers et al., 2008a).

One major assumption of this study is that the significant majority of acoustic signals identified are spinner dolphin signals. Previous passive acoustic monitoring, vessel-based survey efforts, and sightings reported through a participatory science program in Maui Nui identified the following odontocetes in the region: melon-headed whales (Peponocephala electra), short-finned pilot whales (Globicephala macrorhynchus), false killer whales (Pseudorca crassidens), pantropical spotted dolphins (Stenella attenuata), and bottlenose dolphins (Howe et al., 2019; Howe and Lammers, 2021). Melon-headed whales were a rare occurrence in Maui Nui and would be unlikely to have a significant acoustic presence in the recordings of this study (Howe et al., 2019). Similarly, short-finned pilot whales and false killer whales are also unlikely to have a significant acoustic presence, because both species more frequently occupy offshore waters beyond the detection range of the EARs (Howe and Lammers, 2021). Spotted dolphins and bottlenose dolphins had the most spatial overlap with spinner dolphins (Howe et al., 2019). Based on Howe and Lammers (2021) there was a strong diel pattern in which high frequency whistles, attributed to Stenella, had greater acoustic presence in deeper waters at night. This is consistent with the nighttime offshore foraging behavior exhibited by spinner 


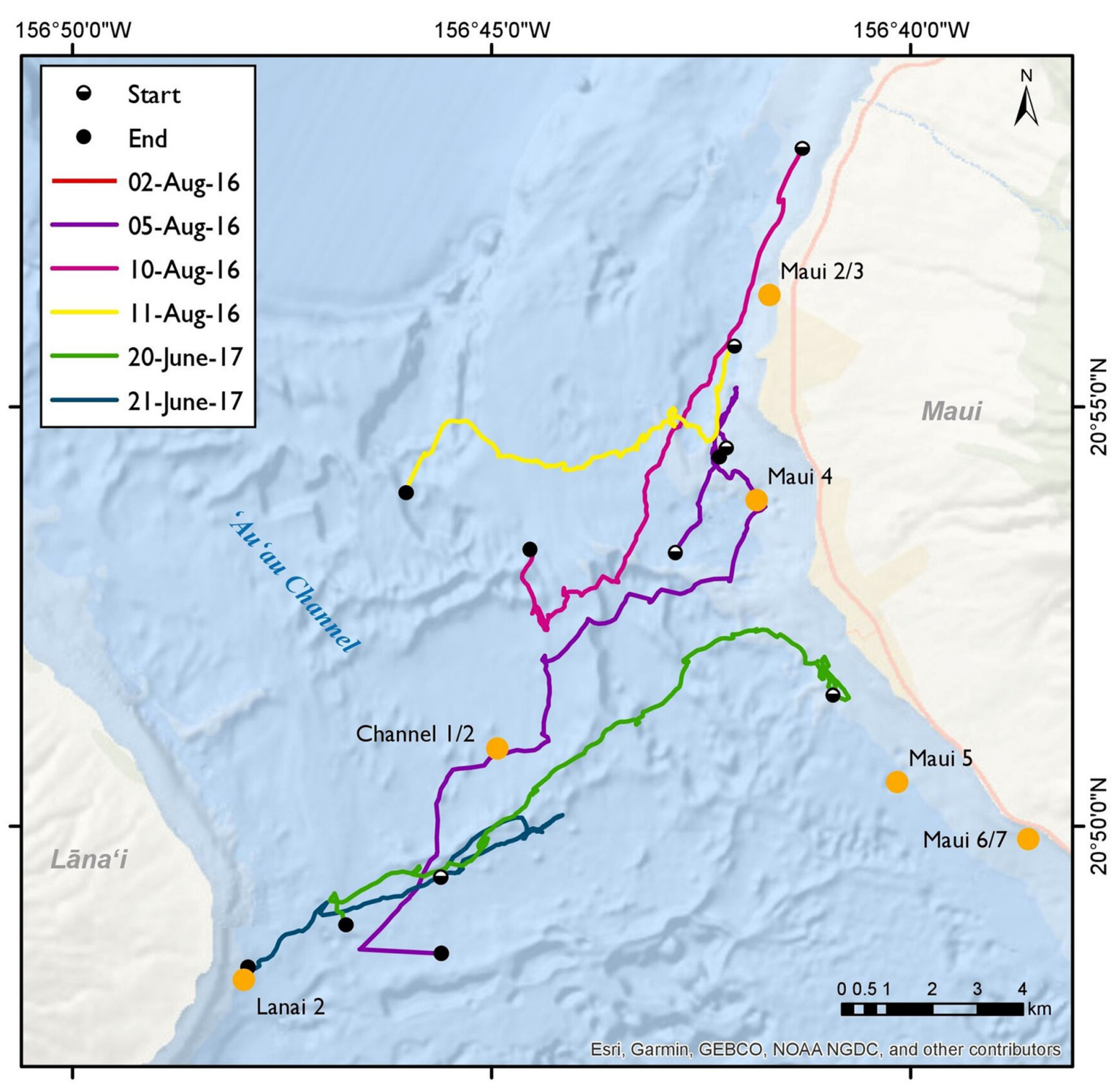

FIGURE 7 | Spinner dolphin sightings from vessel surveys on the 2nd, 5th, 10th, and 11th of August 2016, and the 20th and 21 st of June 2017 in the Maui Nui region. The beginnings and endings of sightings are indicated by white dots and black dots, respectively. Ecological Acoustic Recorder (EAR) locations are marked by orange labels.

TABLE 4 | Starting and ending times, group-size estimates, and the Ecological Acoustic Recorder (EAR) closest to the starting and ending locations of Hawaiian spinner dolphin sightings during vessel surveys with the approximate distance between the sighting and closest EAR $(\mathrm{km})$.

\begin{tabular}{lccccc}
\hline Date & Start time (h) & End time (h) & Group size & Closest EAR start and distance (km) & Closest EAR end and distance (km) \\
\hline $8 / 2 / 2016$ & 0908 & 0923 & 4 & Maui 4, 1.3 km & Maui 4, 1.2 km \\
8/5/2016 & 1218 & 1649 & $150-180$ & Maui 4, 2.0 km & Lanai 2, 4.1 km \\
8/10/2016 & 1132 & 1403 & 50 & Maui 3, 3.3 km & Channel, 4.4 km \\
8/11/2016 & 1053 & 1323 & $50-80$ & Maui 3, $1.3 \mathrm{~km}$ & Channel, 5.9 km \\
6/20/2017 & 1138 & 1541 & 140 & Maui $5,2.3 \mathrm{~km}$ & Lanai 2, 2.4 km \\
6/21/2017 & 1217 & 1436 & 140 & Channel, 3.1 km & Lanai 2, 0.3 km \\
\hline
\end{tabular}

dolphins and other species (Norris et al., 1994; Lammers, 2004). A mirror of this diel pattern was observed at the coastal EAR sites of this study, with more acoustic activity during the daytime hours, coinciding with spinner dolphin resting behavior, and little or no signaling at night. This strong diurnal bias supports the conclusion that the majority of acoustic signals recorded in 
TABLE 5 | Percentage of observations during each vessel-based survey that contained Hawaiian spinner dolphins in each behavioral state (milling, resting, travel-resting, or traveling).

\begin{tabular}{lccccc}
\hline Date & Milling & Resting & Travel-resting & Traveling & $\begin{array}{c}\text { Total number of } \\
\text { observations }\end{array}$ \\
\hline $8 / 2 / 2016$ & $100 \%$ & $0 \%$ & $0 \%$ & $0 \%$ & 1 \\
$8 / 5 / 2016$ & $47 \%$ & $6 \%$ & $0 \%$ & $47 \%$ & 17 \\
$8 / 10 / 2016$ & $0 \%$ & $36 \%$ & $9 \%$ & $55 \%$ & 11 \\
$8 / 11 / 2016$ & $9 \%$ & $36 \%$ & $18 \%$ & $36 \%$ & 11 \\
$6 / 20 / 2016$ & $7 \%$ & $0 \%$ & $60 \%$ & $33 \%$ & 15 \\
$6 / 21 / 2016$ & $9 \%$ & $18 \%$ & $27 \%$ & $45 \%$ & 11 \\
\hline
\end{tabular}

Observations were taken every 15 min within a sighting.

Spinner dolphin groups in multiple states of behavior were assigned the dominant behavioral state (Percentages are rounded to the nearest whole number).

this study was most likely produced by spinner dolphins, which associate with coastal waters more than any of the other species present in the region (Howe et al., 2019). However, a limited contribution of signals from bottlenose and/or spotted dolphins cannot be ruled out.

Acoustic activity observed during nighttime hours, particularly in the Channel 2, Maui 7, and Maui 4 deployments could suggest the presence of spinner dolphins at those times, however, it is more likely to be from bottlenose dolphins (Tursiops truncatus). Bottlenose dolphins occur in small groups off Maui Nui and follow different foraging and resting behavioral cycles than spinner dolphins, and therefore may be more likely to be active in those areas at night (Baird, 2016). Regardless of the dolphin species present, the increase in nighttime acoustic activity at these locations suggests a nocturnal ecological shift, perhaps signaling an emergence or a behavioral change in prey. Seasonal trends in mean AAI were examined at the locations where deployments occurred in both winter and summer: Maui 2 and 3, Channel 1 and 2, and Maui 6 and 7. All three locations had greater mean AAI during summer deployments than winter deployments. Winter deployments coincided with the humpback whale breeding season in Hawai'i (Au et al., 2000). It is possible that spinner dolphins utilize other, less populated areas during this time, as they have been shown to do when exposed to increased human activity (Courbis and Timmel, 2009). Further exploration of seasonal trends at other Maui Nui locations, as well as studying the interactions between humpback whales and spinner dolphins could shed light on whether spinner dolphins do in fact move to new locations to rest and/or reduce their acoustic signaling when humpback whales are present. Another possible explanation for the summer/winter trends in dolphin acoustic activity is a seasonal change in prey distribution. Spinner dolphins have been shown to closely follow both the vertical and horizontal migrations of the mesopelagic boundary community (Benoit-Bird and Au, 2003). Therefore, changes in the spatial patterns of dolphin acoustic activity could reflect changes in prey distribution.

The Maui 1 and Lanai 1 deployments were the sites with the highest levels of AAI after the Oahu deployment. The pattern of occurrence of dolphins at the two locations is inconclusive with respect to establishing whether distinct groups occupy them.
However, the presence of dolphin acoustic detections at Maui 1 (especially in the earlier morning hours of $0600-0800 \mathrm{~h}$ ) is particularly interesting due to the distance from presumed deep water foraging grounds off west Lāna'i (Benoit-Bird and Au, 2003). With Lanai 1's much closer proximity to this foraging area, it seems unlikely that spinner dolphins would occur at Maui 1 approximately the same percentage of the time. A possible explanation could be that dolphins are exploiting a food source in the Pailolo channel (between Maui and Moloka i) north of Maui 1. Acoustic data collected from an EAR for a previous project within the Pailolo channel contained echolocation clicks during nighttime hours, suggesting that foraging by odontocetes does indeed occur in this area (Howe and Lammers, 2021). Further research on the movement of the mesopelagic and epipelagic fish, squid, and shrimp community in the Pailolo channel could provide further evidence about whether spinner dolphins are in fact foraging in this area.

Lastly, the results of this study have important implications for management strategies. Because spinner dolphins use large segments of the west Maui coastline, 'Au'au channel, and south coast of Lāna'i during their daily behavioral cycles rather than consistently resting in a single bay, time-area closures, as have been proposed for Hawai'i Island and O'ahu resting bays, may not provide adequate protection. Time-area closures of the west Maui coastline and 'Au'au channel are unfeasible, as these are important areas of public and commercial activity. Therefore, the proposed statewide 50-yard approach rule would be a more impactful management option for the Maui Nui region.

\section{DATA AVAILABILITY STATEMENT}

The raw data supporting the conclusions of this article will be made available by the authors, without undue reservation.

\section{ETHICS STATEMENT}

Ethical review and approval was not required for the animal study because this study employed passive acoustic monitoring and did not directly interact with free-ranging animals.

\section{AUTHOR CONTRIBUTIONS}

MM processed and analyzed the acoustic data and created the figures and statistical model. Both authors designed the project, wrote the manuscript, contributed to the article, and approved the submitted version.

\section{FUNDING}

MM was funded by the Colonel Willys E. Lord, DVM \& Sandina L. Lord Scholarship Fund through the Hawai'i Institute of Marine Biology at the University of Hawai'i at Mānoa. Ecological Acoustic Recorders and vessel support was provided by the Oceanwide Science Institute. 


\section{ACKNOWLEDGMENTS}

We thank the team of the Oceanwide Science Institute for their field and logistical support: Eden Zang, Lisa Munger, Anke Kügler, Marcus Richter, and Sandy Yarbrough. We would

\section{REFERENCES}

Andrews, K. R., Karczmarski, L., Au, W. W. L., Rickards, S. H., Vanderlip, C. A., Bowen, B. W., et al. (2010). Rolling stones and stable homes: social structure, habitat diversity and population genetics of the Hawaiian spinner dolphin (Stenella longirostris). Mol. Ecol. 19, 732-748. doi: 10.1111/j.1365-294X.2010. 04521.x

Au, W. W. L., Mobley, J., Burgess, W. C., Lammers, M. O., and Nachtigall, P. E. (2000). Seasonal and diurnal trends of chorusing humpback whales wintering in waters off western maui. Mar. Mammal Sci. 16, 530-544. doi: 10.1111/j.17487692.2000.tb00949.x

Baird, R. (2016). The Lives of Hawai'i's Dolphins and Whales: Natural History and Conservation. Honolulu: University of Hawai'i Press.

Bazúa-Durán, C., and Au, W. W. L. (2004). Geographic variations in the whistles of spinner dolphins (Stenella longirostris) of the Main Hawaiian Islands. J. Acoust. Soc. Am. 116, 3757-3769. doi: 10.1121/1.1785672

Benoit-Bird, K. J., and Au, W. W. L. (2003). Prey dynamics affect foraging by a pelagic predator (Stella longirostris) over a range of spatial and temporal scales. Behav. Ecol. Sociobiol. 53, 364-373. doi: 10.1007/s00265-003-0585-4

Benoit-Bird, K. J., Au, W. W. L., Brainard, R. E., and Lammers, M. O. (2001). Diel horizontal migration of the Hawaiian mesopelagic boundary community observed acoustically. Mar. Ecol. Prog. Ser. 217, 1-14. doi: 10.3354/meps 217001

Courbis, S., and Timmel, G. (2009). Effects of vessels and swimmers on behavior of Hawaiian spinner dolphins (Stenella longirostris) in Kealake'akua, Honaunau, and Kauhako bays, Hawai'i. Mar. Mammal Sci. 25, 430-440. doi: 10.1111/j. 1748-7692.2008.00254.x

Danil, K., Maldini, D., and Marten, K. (2005). Patterns of use of maku'a beach, O'ahu, Hawai' $\mathrm{i}$, by spinner dolphins (Stenella longirostris) and potential effects of swimmers on their behavior. Aquat. Mamm. 31, 403-412. doi: 10.1578/AM. 31.4.2005.403

Heenehan, H. L., Johnston, D. W., Van Parijs, S. M., Bejder, L., and Tyne, J. A. (2016a). Acoustic response of Hawaiian spinner dolphins to human disturbance. Proc. Meet. Acoust. 27:010001. doi: 10.1121/2.0000232

Heenehan, H. L., Tyne, J. A., Bejder, L., Van Parijs, S. M., and Johnston, D. W. (2016b). Passive acoustic monitoring of coastally associated Hawaiian spinner dolphins, Stenella longirostris, ground-truthed through visual surveys. J. Acoust. Soc. Am. 140, 206-215. doi: 10.1121/1.4955094

Heenehan, H. L., Van Parijs, S. M., Bejder, L., Tyne, J. A., and Johnston, D. W. (2017). Differential effects of human activity on Hawaiian spinner dolphins in their resting bays. Glob. Ecol. Conserv. 10, 60-69. doi: 10.1016/j.gecco.2017. 02.003

Hofner, B., Mayr, A., Robinzonov, N., and Schmid, M. (2014). Model-based boosting in R - A hands-on tutorial using the R Package mboost. Comput. Stat. 29, 3-35. doi: 10.1007/s00180-012-0382-5

Hofner, B., Mayr, A., and Schmid, M. (2016). gamboostLSS: an r package for model building and variable selection in the GAMLSS Framework. J. Stat. Softw. 74:1. doi: 10.18637/jss.v074.i01

Howe, M., and Lammers, M. O. (2021). Investigating the diel occurrence of odontocetes around the maui nui region using passive acosutic techniques. $\mathrm{Pac}$. Sci. 75, 147-161. doi: 10.7810/9781988545486_21

Howe, M., Lammers, M. O., and Baird, R. W. (2019). Participatory science and directed survey methods: a case study with odontocetes in the maui nui region of the Hawaiian Islands. J. Cetacean Res. Manag. 20, 101-109. doi: 10.47536/ jcrm.v20i1.235

Karczmarski, L., Würsig, B., Gailey, G., Larson, K. W., and Vanderlip, C. (2005). Spinner dolphins in a remote Hawaiian atoll: social grouping and population structure. Behav. Ecol. 16, 675-685. doi: 10.1093/beheco/ari028

Klinowska, M. (1991). Dolphins, porpoises and whales of the world: the IUCN red data book. Gland: IUCN. also like to acknowledge Kimball Millikan, Dan Fitzgerald, Leann Castle, and Karen Bryan for providing their time and vessel support to deploy and refurbish instruments off O'ahu, and Emi and Russell Young for their help during our Maui field work.

Lammers, M. O. (2004). Occurrence and behavior of hawaiian spinner dolphins (stenella longirostris) along oahu's leeward and south shores. Aquat. Mamm. 30, 237-250. doi: 10.1578/AM.30.2.2004.237

Lammers, M. O. (2019). "Spinner Dolphins of Islands and Atolls," in Ethology and Behavioral Ecology of Odontocetes, ed. B. Wursig (New York, NY: Springer), 369-385. doi: 10.1007/978-3-030-16663-2_17

Lammers, M. O., and Au, W. W. L. (2003). Directionality in the whistles of hawaiian spinner dolphins (Stenella longirostris): a signal feature to cue direction of movement? Mar. Mammal Sci. 19, 249-264. doi: 10.1111/j.17487692.2003.tb01107.x

Lammers, M. O., Bernasconi, S., Au, W. W. L., Wong, K., and Brainard, R. (2008a). Patterns of coastal use by Hawaiian spinner dolphins (Stenella longirostris) observed using passive acoustic monitoring. J. Acoust. Soc. Am 124:2483. doi: $10.1121 / 1.4782748$

Lammers, M. O., Brainard, R. E., Au, W. W. L., Mooney, T. A., and Wong, K. B. (2008b). An ecological acoustic recorder (EAR) for long-term monitoring of biological and anthropogenic sounds on coral reefs and other marine habitats. J. Acoust. Soc. Am. 123, 1720-1728. doi: 10.1121/1.2836780

Lammers, M. O., Castellote, M., Small, R. J., Atkinson, S., Jenniges, J., Rosinski, A., et al. (2013). Passive acoustic monitoring of cook inlet beluga whales (Delphinapterus leucas). J. Acoust. Soc. Am. 134, 2497. doi: 10.1121/1.48 16575

Lammers, M. O., and Munger, L. M. (2016). "From Shrimp to Whales: Biological Applications of Passive Acoustic Monitoring on a Remote Pacific Coral Reef," in Listening in the Ocean: New Discoveries and Insights on Marine Life from Autonomous Passive Acoustic Recorders, eds W. W. L. Au and M. O. Lammers (New York, NY: Springer), 61-81. doi: 10.1007/978-1-49393176-7_4

Lammers, M. O., and Oswald, J. N. (2015). “Analyzing the acoustic communication of dolphins," in Dolphin Communication and Cognition: Past, Present, and Future, eds D. Herzing and C. M. Johnson (Cambridge, MA: The MIT Press), 107-137.

Lammers, M. O., Schotten, M., and Whitlow, W. L. A. (2006). The spatial context of free-ranging Hawaiian spinner dolphins (Stenella longirostris) producing acoustic signals. J. Acoust. Soc. Am. 119, 1244-1250. doi: 10.1121/1.21 51804

Maloney, K. O., Schmid, M., and Weller, D. E. (2012). Applying additive modelling and gradient boosting to assess the effects of watershed and reach characteristics on riverine assemblages. Methods Ecol. Evol. 3, 116-128. doi: 10.1111/j.2041210X.2011.00124.x

McElligott, M. M. (2018). Investigating behavioral and habitat-use patterns of spinner dolphins (Stenella longirostris) in the Maui Nui region using acoustic data. (Unpublished master's thesis). Mānoa: University of Hawai'i

NOAA. (2016). Protective regulations for hawaiian spinner dolphins under the marine mammal protection act. Fed. Regist. 81, 57854-57876.

Norris, K. S., Wursig, B., Wells, R. S., Wursig, M., Brownlee, S. M., Johnson, C., et al. (1994). The Hawaiian Spinner Dolphin. Berkeley: University of California Press.

Price, J. P., and Elliott-Fisk, D. (2004). Topographic history of the Maui Nui complex, Hawai'i, and its implications for biogeography. Pacific Sci. 58, 27-45. doi: $10.1353 /$ psc.2004.0008

R Core Team. (2015). $R$ : A language and environment for statistical computing. $R$ Foundation forStatistical Computing. Vienna: R Core Team.

Schmid, M., Wickler, F., Maloney, K. O., Mitchell, R., Fenske, N., and Mayr, A. (2013). Boosted Beta Regression. PLoS One 8:61623. doi: 10.1371/journal.pone. 0061623

Sewe, M. O., Tozan, Y., Ahlm, C., and Rocklöv, J. (2017). Using remote sensing environmental data to forecast malaria incidence at a rural district hospital in Western Kenya. Sci. Rep 7:2560. doi: 10.1038/s41598-01702560-z 
Stack, S. H., Olson, G. L., Neamtu, V., Machernis, A. F., Baird, R. W., and Currie, J. J. (2020). Identifying spinner dolphin Stenella longirostris longirostris movement and behavioral patterns to inform conservation strategies in Maui Nui, Hawai'i. Marine Ecol. Prog. Ser. 2020:13347. doi: 10.3354/meps 13347

Thorne, L. H., Johnston, D. W., Urban, D. L., Tyne, J., Bejder, L., Baird, R. W., et al. (2012). Predictive modeling of spinner dolphin (Stenella longirostris) resting habitat in the main Hawaiian Islands. PLoS One 7:43167. doi: 10.1371/journal. pone. 0043167

Tyne, J. A., Johnston, D. W., Christiansen, F., and Bejder, L. (2017). Temporally and spatially partitioned behaviours of spinner dolphins: implications for resilience to human disturbance. $R$. Soc. Open Sci. 4:160626. doi: 10.1098/rsos. 160626

Tyne, J. A., Johnston, D. W., Rankin, R., Loneragan, N. R., and Bejder, L. (2015). The importance of spinner dolphin (Stenella longirostris) resting habitat: Implications for management. J. Appl. Ecol. 52, 621-630. doi: 10.1111/13652664.12434

Tyne, J. A., Pollock, K. H., Johnston, D. W., and Bejder, L. (2014). Abundance and survival rates of the Hawai' $i$ Island associated spinner dolphin (Stenella longirostris) stock. PLoS One 9:86132. doi: 10.1371/journal.pone.0086132
Wiggins, S. M. (2003). Autonomous acoustic recording packages (ARPs) for long-term monitoring of whale sounds. MTS J. 37, 13-22. doi: 10.4031/ 002533203787537375

Conflict of Interest: The authors declare that the research was conducted in the absence of any commercial or financial relationships that could be construed as a potential conflict of interest.

Publisher's Note: All claims expressed in this article are solely those of the authors and do not necessarily represent those of their affiliated organizations, or those of the publisher, the editors and the reviewers. Any product that may be evaluated in this article, or claim that may be made by its manufacturer, is not guaranteed or endorsed by the publisher.

Copyright $\odot 2021$ McElligott and Lammers. This is an open-access article distributed under the terms of the Creative Commons Attribution License (CC BY). The use, distribution or reproduction in other forums is permitted, provided the original author(s) and the copyright owner(s) are credited and that the original publication in this journal is cited, in accordance with accepted academic practice. No use, distribution or reproduction is permitted which does not comply with these terms. 